Federal Reserve Bank of Minneapolis

The CAPM Debate (р. 2)

Ravi Jagannathan

Ellen R. McGrattan

\title{
The Growth Effects
}

of Monetary Policy (p. 18)

V. V. Chari

Larry E. Jones

Rodolfo E. Manuelli 
Federal Reserve Bank of Minneapolis

\section{Quarterly Review vol.19, No.4}

ISSN 0271-5287

This publication primarily presents economic research aimed at improving policymaking by the Federal Reserve System and other governmental authorities.

Any views expressed herein are those of the authors and not necessarily those of the Federal Reserve Bank of Minneapolis or the Federal Reserve System.

Editor: Arthur J. Rolnick

Associate Editors: S. Rao Aiyagari, Edward J. Green, Preston J. Miller, Warren E. Weber

Economic Advisory Board: John H. Boyd, V. V. Chari, Edward C. Prescott, James A. Schmitz, Jr.

Managing Editor: Kathleen S. Rolfe

Article Editors: Kathleen S. Rolfe, Jenni C. Schoppers

Designer: Phil Swenson

Associate Designer: Lucinda Gardner

Typesetter: Jody Fahland

Technical Assistants: Daniel M. Chin, Shawn Hewitt, Maureen O'Connor

Circulation Assistant: Cheryl Vukelich

The Quarterly Review is published by the Research Department of the Federal Reserve Bank of Minneapolis. Subscriptions are available free of charge.

Quarterly Review articles that are reprints or revisions of papers published elsewhere may not be reprinted without the written permission of the original publisher. All other Quarterly Review articles may be reprinted without charge. If you reprint an article, please fully credit the source - the Minneapolis Federal Reserve Bank as well as the Quarterly Review - and include with the reprint a version of the standard Federal Reserve disclaimer (italicized above). Also, please send one copy of any publication that includes a reprint to the Minneapolis Fed Research Department.

A list of past Quarterly Review articles and some electronic files of them are available through the Minneapolis Fed's home page on the World Wide Web: http://woodrow.mpls.frb.fed.us.
Comments and questions about the Quarterly Review may be sent to

\section{Quarterly Review}

Research Department

Federal Reserve Bank of Minneapolis

P.O. Box 291

Minneapolis, Minnesota 55480-0291

(612-340-2341 / FAX 612-340-2366).

Subscription requests may also be sent to the circulation assistant at clv@res.mpls.frb.fed.us. Editorial comments and questions may also be sent to the managing editor at ksr@res.mpls.frb.fed.us. 


\section{The CAPM Debate*}

\author{
Ravi Jagannathan \\ Visitor \\ Research Department \\ Federal Reserve Bank of Minneapolis \\ and Piper Jaffray Professor of Finance \\ Carlson School of Management \\ University of Minnesota
}

\author{
Ellen R. McGrattan \\ Senior Economist \\ Research Department \\ Federal Reserve Bank of Minneapolis
}

Most large U.S. companies have built into their capital budgeting process a theoretical model that economists are now debating the value of. This is the capital asset pricing model (the CAPM) developed 30 years ago by Sharpe (1964) and Lintner (1965). This model was the first apparently successful attempt to show how to assess the risk of the cash flow from a potential investment project and to estimate the project's cost of capital, the expected rate of return that investors will demand if they are to invest in the project. Until recently, empirical tests of the CAPM supported the model. But in 1992, tests by Fama and French did not; they said, in effect, that the CAPM is useless for precisely what it was developed to do. Since then, researchers have been scrambling to figure out just what's going on. What's wrong with the CAPM? Are the Fama and French results being interpreted too broadly? Must the CAPM be abandoned and a new model developed? Or can the CAPM be modified in some way to make it still a useful tool? ${ }^{1}$

In this article, we don't take sides in the CAPM debate; we merely try to describe the debate accurately. We start by describing the data the CAPM is meant to explain. Then we develop a version of the model and describe how it measures risk. And finally we describe the results of competing empirical studies of the model's validity.

\section{The Facts}

Let's start by examining the facts: the historical data on average returns for various types of assets. We focus on historical average returns because the averages of returns over long time horizons are good estimates of expected returns. And estimating expected returns for different types of assets is a significant part of what the CAPM is supposed to be able to do well.

Table 1 provides a summary of the average return history for four types of assets: stocks for large and small firms, long-term U.S. Treasury bonds, and short-term U.S. Treasury bills. ${ }^{2}$

For each sample period, we report average annual rates of return. If investors have rational expectations, then the average returns over a fairly long horizon should be a rea-

\footnotetext{
*The authors thank Jaeuk Khil for research assistance and Gordon Alexander, V. V. Chari, David Marshall, David Runkle, and especially John Boyd for helpful comments.

${ }^{1}$ For a discussion of how corporate managers use models like the CAPM, see the box displayed later in the article.

${ }^{2}$ According to the description given by the source for these data, Ibbotson Associates 1992, the common stock returns are based on Standard \& Poor's composite index. This index includes 500 stocks now, but it included only 90 stocks before March 1957 . For the period 1926-81, the small-firm stock index consisted of stocks in the smallest quintile of firms in terms of their market value of equity (their share price times shares outstanding) listed in the New York Stock Exchange; the portfolio composition is rebalanced once every five years. Starting in 1982, the small-firm stock index corresponds to the Dimensional Fund Advisors' Small Company Fund. For the period 1926-76, the total returns on long-term U.S. government bonds are from the Center for Research in Security Prices (CRSP) at the University of Chicago Graduate School of Business. Each year one bond portfolio is constructed with a maturity of about 20 years. For the period 1977-91, data from the Wall Street Journal are used to compute the total returns on bond funds. For U.S. Treasury bill returns, data from the CRSP U.S. government bond file are used through 1976. Data reported in the Wall Street Journal are used for the period thereafter.
} 
Table 1

Financial Asset Returns and Inflation

During 1926-91

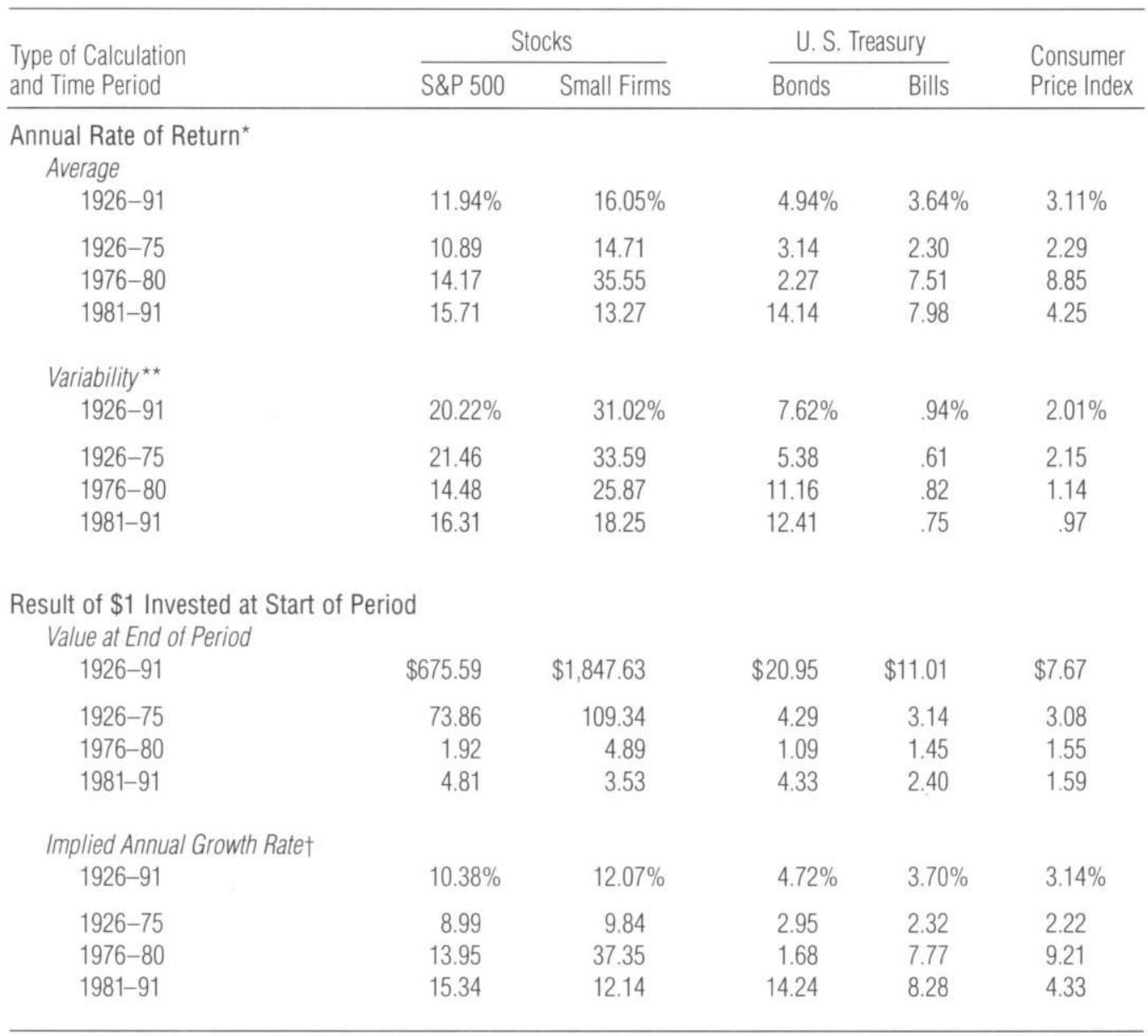

"The annual rate of return is the asset's monthly return multiplied by 12 .

* The variability of the return is its standard deviation multiplied by the square root of 12 .

tThe implied annual growth rate is calculated by this formula:

(Value of $\$ 1$ at end of period) $1 / n-1$, where $n$ is the number of years in the period.

Source: Ibbotson Associates 1992

sonable measure of expected returns. Notice that the historical returns on different types of assets are substantially different. The fact that investors did hold these assets implies that investors would demand vastly different rates of return for investing in different projects.
To the extent that the assets are claims to cash flows from a variety of real activities, these facts support the view that the cost of capital is very different for different projects. During the 66-year period from 1926 to 1991 , for example, Standard \& Poor's 500-stock price index (the 
S\&P 500) earned an average annual return of 11.9 percent whereas U.S. Treasury bills (T-bills) earned only 3.6 percent. Since the average annual inflation rate was 3.1 percent during this period, the average real return on T-bills was hardly different from zero. S\&P stocks, therefore, earned a hefty risk premium of 8.3 percent over the nominally risk-free return on T-bills. The performance of the stocks of small firms was even more impressive; they earned an average annual return of 16.1 percent.

To appreciate the economic importance of these differences in annual average, consider how the value of a dollar invested in each of these types of assets in 1926 would have changed over time. As Table 1 shows, by 1991, \$1 invested in S\&P stocks would be worth about $\$ 675$, whereas \$1 invested in T-bills would be worth only $\$ 11$. That's not much considering the fact that a market basket of goods costing \$1 in 1926 would cost nearly \$8 in 1991 .

For another perspective, consider what could have been purchased in 1991 if $\$ 10$ had been invested in each of these assets in 1926. If $\$ 10$ were invested in small-firm stocks in 1926, by 1991 it would be worth an impressive $\$ 18,476$. That's enough to cover one year of tuition in most prestigious universities in the United States. Meanwhile, $\$ 10$ invested in T-bills would be worth only $\$ 110$ in 1991, or enough to buy dinner for two in a nice restaurant. $^{3}$

Notice in Table 1 that the assets with higher average returns over 1926-91 also had more variable returns. This correspondence suggests that the higher average returns were compensation for some perceived higher risk. For example, small-firm stocks, which yielded the highest return in this period, had the highest standard deviation too. Similarly, in the first two subperiods, 1926-75 and 197680 , small-firm stocks had both the highest return and the highest standard deviation.

However, something happened in the last subperiod, 1981-91, according to Table 1. Long-term government bonds did extremely well. A dollar invested in Treasury bonds at the end of 1980 would have grown to more than $\$ 4$ by the end of 1991 , which implies a high annual rate of return (14.2 percent). The risk premium (over T-bills) on the S\&P 500 for the 1981-91 subperiod was 7.7 percent, not much different from that for the entire sample period. However, during this subperiod, the average annual return on T-bills of 8 percent was substantially more than the average inflation rate of 4.3 percent. This unusual subperiod suggests that the sampling errors for the entire period computed using conventional time series methods (which assume that the entire time series is generated from the same underlying distribution) may overstate the precision with which the sample averages measure the corresponding population expectations.

Clearly, though, across all subperiods, the time series of realized returns on these four types of assets are substantially different in both their average and their volatility. This can be seen in another way by examining Chart 1. There we display over the sample period 1926-91 the logarithm of the values of one dollar invested in each asset in January 1926. For example, the values plotted for December 1991 are logarithms of the numbers in Table 1. We plotted the logarithms of the values so they could all be easily displayed together on one chart and compared; the values themselves are vastly different. The chart is intended to further illustrate the great differences in the paths of returns across the four assets.

These great differences are unlikely to be entirely accidental. If investors had reasonable expectations in 1926, they would have guessed that something like this would be the outcome 66 years later, but still they were content to invest in portfolios that included all of these different assets. A question that needs to be answered is, In what way are these assets different that makes investors content to hold every one of them even though their average returns are so different? For example, in what way are small-firm stocks different from S\&P 500 stocks that makes investors satisfied with an 8.3 percent risk premium (over T-bills) for the latter whereas they require a 12.4 percent risk premium for the former?

\section{The Model}

The CAPM was developed, at least in part, to explain the differences in risk premium across assets. According to the CAPM, these differences are due to differences in the riskiness of the returns on the assets. The model asserts that the correct measure of riskiness is its measureknown as beta - and that the risk premium per unit of riskiness is the same across all assets. Given the risk-free rate and the beta of an asset, the CAPM predicts the expected risk premium for that asset. In this section, we will derive a version of the CAPM. In the next section, we will examine whether the CAPM is actually consistent with the average return differences.

\footnotetext{
${ }^{3}$ Table 1 also reports the implied annual returns that would produce those dollar values. To calculate these returns, we first calculate the value of the asset if $\$ 1$ were invested in the first year of the period. We then raise that value to the power of 1 over the number of years for the period and subtract 1 .
} 
Chart 1

How the Value of $\$ 1$ Invested in Four Assets

Would Have Changed Since 1926

Monthly, 1926-91

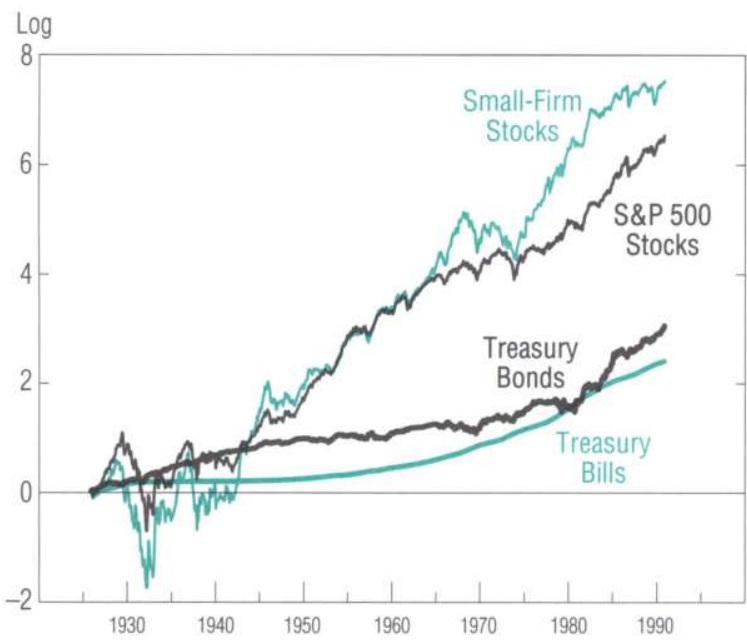

Source of basic data: Ibbotson Associates 1992

To derive the CAPM, we start with the simple problem of choosing a portfolio of assets for an arbitrarily chosen investor. To set up the problem, we need a few definitions. Let $R_{0}$ be the return (that is, one plus the rate of return) on the risk-free asset (asset 0 ). By investing $\$ 1$, the investor will get $\$ R_{0}$ for sure. In addition, assume that the number of risky assets is $n$. The risky assets have returns that are not known with certainty at the time the investments are made. Let $\alpha_{i}$ be the fraction of the investor's initial wealth that is allocated to asset $i$. Then $R_{i}$ is the return on asset $i$. Let $R_{m}$ be the return on the entire portfolio (that is, $\sum_{i=0}^{n}$ $\alpha_{i} R_{i}$ ). Here $R_{i}$ is a random variable with expected value $E R_{i}$ and variance $\operatorname{var}\left(R_{i}\right)$, where variance is a measure of the volatility of the return. The covariance between the return of asset $i$ and the return of asset $j$ is represented by $\operatorname{cov}\left(R_{i}, R_{j}\right)$. Covariance provides a measure of how the returns on the two assets, $i$ and $j$, move together.

Suppose that the investor's expected utility can be represented as a function of the expected return on the investor's portfolio and its variance. In order to simplify notation without losing generality, assume that the investor can choose to allocate wealth to three assets: $i=0,1$, or 2 . Then the problem is to choose fractions $\alpha_{0}, \alpha_{1}$, and $\alpha_{2}$ that maximize

$$
V\left(E R_{m}, \operatorname{var}\left(R_{m}\right)\right)
$$

subject to

$$
\begin{aligned}
& \alpha_{0}+\alpha_{1}+\alpha_{2}=1 \\
& E R_{m}=\alpha_{0} R_{0}+\alpha_{1} E R_{1}+\alpha_{2} E R_{2} \\
& \operatorname{var}\left(R_{m}\right)=\alpha_{1}^{2} \operatorname{var}\left(R_{1}\right)+\alpha_{2}^{2} \operatorname{var}\left(R_{2}\right) \\
& +2 \alpha_{1} \alpha_{2} \operatorname{cov}\left(R_{1}, R_{2}\right) .
\end{aligned}
$$

The objective function $V$ is increasing in the expected return, $\partial V / \partial E R_{m}>0$; decreasing in the variance of the return, $\partial V / \partial \operatorname{var}\left(R_{m}\right)<0$; and concave. These properties imply that there is a trade-off between expected returns and the variance of returns. The constraint in equation (2) ensures that the fractions sum to 1. Equations (3) and (4) follow from the definition of the rate of return on the wealth portfolio of the investor, $R_{m}$.

Substituting $1-\alpha_{1}-\alpha_{2}$ for $\alpha_{0}$ in equation (1) and taking the derivative of $V$ with respect to $\alpha_{1}$ and $\alpha_{2}$ yields the following conditions that must hold at an optimum:

$$
\begin{aligned}
& \left(E R_{1}-R_{0}\right) V_{1}+2\left[\alpha_{1} \operatorname{var}\left(R_{1}\right)+\alpha_{2} \operatorname{cov}\left(R_{1}, R_{2}\right)\right] V_{2}=0 \\
& \left(E R_{2}-R_{0}\right) V_{1}+2\left[\alpha_{2} \operatorname{var}\left(R_{2}\right)+\alpha_{1} \operatorname{cov}\left(R_{1}, R_{2}\right)\right] V_{2}=0
\end{aligned}
$$

where $V_{j}$ is the partial derivative of $V$ with respect to its $j$ th argument, for $j=1,2$. Now consider multiplying equation (5) by $\alpha_{1}$ and equation (6) by $\alpha_{2}$ and summing the results:

$$
\begin{aligned}
& {\left[\alpha_{1}\left(E R_{1}-R_{0}\right)+\alpha_{2}\left(E R_{2}-R_{0}\right)\right] V_{1}} \\
& +2\left\{\alpha_{1}\left[\alpha_{1} \operatorname{var}\left(R_{1}\right)+\alpha_{2} \operatorname{cov}\left(R_{1}, R_{2}\right)\right]\right. \\
& \left.\quad+\alpha_{2}\left[\alpha_{2} \operatorname{var}\left(R_{2}\right)+\alpha_{1} \operatorname{cov}\left(R_{1}, R_{2}\right)\right]\right\} V_{2}=0 .
\end{aligned}
$$

Using the definitions of $E R_{m}$ and $\operatorname{var}\left(R_{m}\right)$, we can write this more succinctly:

$$
\left(E R_{m}-R_{0}\right) V_{1}+2 \operatorname{var}\left(R_{m}\right) V_{2}=0 .
$$

The expressions in (5), (6), and (8) can all be written as explicit functions of the ratio $V_{2} / V_{1}$, and then the first two expressions [from (5) and (6)] can be equated to the third [from (8)]. This yields the following two relationships:

$$
E R_{i}-R_{0}=\left[\operatorname{cov}\left(R_{i}, R_{m}\right) / \operatorname{var}\left(R_{m}\right)\right]\left(E R_{m}-R_{0}\right)
$$


for $i=1,2$. In fact, even for the more general case, where $n$ is not necessarily equal to 2 , equation (9) holds. Let $\operatorname{cov}\left(R_{i}, R_{m}\right) / \operatorname{var}\left(R_{m}\right)$ be the beta of asset $i$, or $\beta_{i}$. Then we have

$$
E R_{i}=R_{0}+\left(E R_{m}-R_{0}\right) \beta_{i}
$$

for all $i=1, \ldots, n$.

A portfolio is said to be on the mean-variance frontier of the return/variance relationship if no other choice of weights $\alpha_{0}, \alpha_{j}$ (for $j=1,2, \ldots, n$ ) yields a lower variance for the same expected return. The portfolio is said to be on the efficient part of the frontier if, in addition, no other portfolio has a higher expected return. The optimally chosen portfolio for the problem in equations (1)-(4) has this property. In fact, equation (10) will continue to hold if the return $R_{m}$ is replaced by the return on any mean-variance efficient portfolio other than the risk-free asset.

Note that the return $R_{m}$ in (10) is the return for one investor's wealth portfolio. But equation (10) holds for every mean-variance efficient portfolio, and $V$ need not be the same for all investors. A property of mean-variance efficient portfolios is that portfolios of them are also meanvariance efficient. If we define the market portfolio to be a weighted sum of individual portfolios with the weights determined by the fractions of total wealth held by individuals, then the market portfolio is mean-variance efficient too. Therefore, an equation of the form given by (10) also holds for the market portfolio.

In fact, equation (10) with $R_{m}$ equal to the return on the market portfolio is the key relation for the CAPM. This relation implies that all assets $i$ have the same ratios of reward, measured as the expected return in excess of the risk-free rate $\left(E R_{i}-R_{0}\right)$, to risk $\left(\beta_{i}\right)$. This is consistent with the notion that investors trade off return and risk.

In specifying the problem of a typical investor [in (1)(4)], we assumed that a risk-free asset is available. If we drop this assumption and set $\alpha_{0}=0$ from the start, then we obtain a slightly different relationship between return and risk than is given in (10). In particular, Black (1993) shows that without a risk-free asset, expected returns on the risky assets satisfy this relationship:

$$
E R_{i}=E R_{z}+\left(E R_{m}-E R_{z}\right) \beta_{i}
$$

where $R_{z}$ is the return on a zero-beta portfolio [that is, $\left.\operatorname{cov}\left(R_{z}, R_{m}\right)=0\right], R_{m}$ is the return on the market portfolio, and $\beta_{i}=\operatorname{cov}\left(R_{i}, R_{m}\right) / \operatorname{var}\left(R_{m}\right)$.
We now provide an interpretation of beta in (10) or (11) as a measure of the asset's contribution to portfolio risk. Consider a portfolio $p$ of assets that earns return $R_{p}$ and has standard deviation $S_{p}=\left(\operatorname{var} R_{p}\right)^{1 / 2}$. Let the standard deviation of an arbitrary asset $i$ be $S_{i}$ and the covariance between asset $i$ 's return and that of the portfolio be $C_{i, p}$. Now consider a new portfolio with $x_{i}$ invested in asset $i$, $-x_{i}$ invested in the risk-free asset, and $x_{p}$ invested in the original portfolio. That is, consider modifying the portfolio of an investor who currently holds $x_{p}$ in portfolio $p$ by borrowing $\$ x_{i}$ and investing it in asset $i$. The standard deviation of the new portfolio is then

$$
S=\left(x_{i}^{2} S_{i}^{2}+x_{p}^{2} S_{p}^{2}+2 x_{i} x_{p} C_{i, p}\right)^{1 / 2} .
$$

Note that the derivative of $S$ with respect to $x_{i}$ is

$$
d S / d x_{i}=\left(x_{i} S_{i}^{2}+x_{p} C_{i, p}\right) / S .
$$

This derivative measures how much the standard deviation (or risk) of the whole portfolio changes with a small change in the amount invested in asset $i$. If we evaluate this derivative at $x_{i}=0$ and $x_{p}=1$, then we find that

$$
d S /\left.d x_{i}\right|_{x_{i}=0, x_{p}=1}=C_{i, p} / S_{p}=\left(C_{i, p} / S_{p}^{2}\right) S_{p}=\beta_{i} S_{p} .
$$

Notice that $d S / d x_{i}=\beta_{i} S_{p}$. That is, at the margin, an additional dollar invested in asset $i$ (by borrowing the dollar) increases the standard deviation of the portfolio by $\beta_{i} S_{p}$ and not by $S_{i}{ }^{4}$ Since $S_{p}$ does not depend on the particular asset $i, \beta_{i}$ measures the relevant risk up to a scale multiple. In other words, when assets are held in a portfolio, the right measure of the increase in the portfolio risk due to an additional dollar of investment in the asset is the beta of the asset, not the volatility of its return.

To see this more clearly, consider the following example. Suppose an investor is holding $\$ 1,000$ in a portfolio that includes stocks of all firms listed on the New York Stock Exchange (NYSE) and the American Stock Exchange (AMEX), where the investment proportions are the same as the relative market capitalization of the stocks of the firms. Suppose that all dividends are reinvested in

\footnotetext{
${ }^{4}$ Note that we could have started our derivations of equation (10) by using the fact that investors trade off expected returns (that is, means) and risk (that is, variances) when making portfolio decisions. Suppose that investors are indifferent between assets that yield the same return/risk ratios; that is, suppose that $\left(d R / d x_{i}\right) /\left.\left(d S / d x_{i}\right)\right|_{x_{j}=0, x_{i}=1}$ is constant for all $i$, where $R=x_{i} R_{i}+x_{p} R_{p}-x_{i} R_{0}$. Then $\left(E R_{i}-R_{0}\right) / \beta_{i}$ must be constant; hence, equation (10) holds.
} 


\section{How the CAPM Helps Corporate Managers}

Models like the capital asset pricing model (the CAPM) help corporate managers by providing them with a practical way to learn about how investors judge the riskiness of potential investment opportunities. This helps managers use the resources of their firms more efficiently.

\section{The Manager's Problem}

In modern industrial economies, managers don't easily know what the firm's owners want them to do. Ownership and management are typically quite separate. Managers are hired to act in the interests of owners, who hold stock in the corporation but are otherwise not involved in the business.

Owners send some general messages to managers through the stock market. If stockholders do not like what managers are doing, they sell their stocks, and the market value of the firm's stock drops. The representatives of stockholders on the firm's board of directors notice this and turn to the managers for corrective action. In this way, therefore, stock prices act like an oversight mechanism. They monitor the activities of managers by aggregating the opinions of the stockholders.

However, stock prices don't act fast enough. They don't give managers specific directions ahead of time about which projects to pursue and which to avoid. Managers must make these capital expenditure decisions on their own and then later find out, by the stock market's reaction, whether or not the firm's owners approve.

Disapproval can be costly. In the United States in 1992, for example, capital expenditures by the corporate business sector (excluding farming and finance) totaled \$397 billion (or 6.6 percent of the annual gross domestic product). These expenditures usually cannot be recovered if stockholders disapprove of them.

\section{The Classic Solution}

In view of this, capital budgeting has a central role in both the theory and the practice of managerial finance.

Theory suggests one simple rule for corporate managers to follow when making capital expenditure decisions: Maximize the value of the firm. Then, if some stockholders disagree with management decisions, they can sell their stock and be at least as well off as if management had made dif- ferent decisions. This idea is the basis for the classic theoretical recommendation that managers only invest in those projects which have a positive net present value.

In practice, however, following that simple rule is not simple. It requires, among other things, estimating the net present value of every project under consideration. Corporations thus spend a substantial amount of resources evaluating potential projects.

A key input to that process is the cost to the firm of financing capital expenditures, known more simply as the cost of capital. This is the expected rate of return that investors will require for investing in a specific project or financial asset. The cost of capital typically depends on the particular project and the risk associated with it. To be able to evaluate projects effectively, managers must understand how investors assess that risk and how they determine what risk premium to demand.

\section{The CAPM's Role}

Providing such an understanding is the focus of most research in the area of asset pricing. An asset pricing model provides a method of assessing the riskiness of cash flows from a project. The model also provides an estimate of the relationship between that riskiness and the cost of capital (or the risk premium for investing in the project).

According to the CAPM, the only relevant measure of a project's risk is a variable unique to this model, known as the project's beta. In the CAPM, the cost of capital is an exact linear function of the rate on a risk-free project and the beta of the project being evaluated. A manager who has an estimate of the beta of a potential project can use the CAPM to estimate the cost of capital for the project.

If the CAPM captures investors' behavior adequately, then the historical data should reveal a positive linear relation between the average return on financial assets and their betas. Also, no other measure of risk should be able to explain the differences in average returns across financial assets that are not explained by CAPM betas. Empirical studies of the CAPM have supported this model on both of those points - until recently, as the accompanying article describes. 
Table 2

Selected Stock Returns, Volatilities, and Betas

During 1972-91

\begin{tabular}{|c|c|c|c|c|}
\hline \multirow[b]{3}{*}{ Firm (i) } & & & \multicolumn{2}{|c|}{ Relation to Total Portfolio* } \\
\hline & \multicolumn{2}{|c|}{ Monthly Rate of Return } & \multirow{2}{*}{ Beta $(\beta)$} & \multirow{2}{*}{$\begin{array}{l}\text { Effect on Portfolio } \\
\text { S.D. of } \$ 1 \\
\text { Stock Increase } \\
\left(\partial S / \partial x_{i}\right)\end{array}$} \\
\hline & Mean & S.D. $\left(S_{i}\right)$ & & \\
\hline American Telephone and Telegraph & 1.19 & 5.36 & .552 & 2.63 \\
\hline Bristol-Myers Squibb & 1.56 & 7.08 & .986 & 4.70 \\
\hline Coca-Cola & 1.40 & 6.75 & .917 & 4.37 \\
\hline Consolidated Edison & 1.61 & 7.38 & .566 & 2.70 \\
\hline Dayton Hudson & 1.53 & 9.69 & 1.191 & 5.68 \\
\hline Digital Equipment & 1.13 & 10.25 & 1.278 & 6.09 \\
\hline Exxon & 1.47 & 5.26 & .729 & 3.47 \\
\hline Ford Motor & 1.15 & 8.32 & .968 & 4.61 \\
\hline International Business Machines & .61 & 6.03 & .769 & 3.66 \\
\hline McDonald's & 1.37 & 8.15 & 1.129 & 5.38 \\
\hline McGraw-Hill & 1.41 & 8.15 & 1.075 & 5.12 \\
\hline
\end{tabular}

"The total portiflio is $\$ 1,000$ invested in all stocks traded on the NYSE and AMEX.

Source: Center for Research on Security Prices, University of Chicago

that portfolio. Now suppose that the investor borrows $\$ 1$ and invests in stocks of one of the randomly selected 11 firms listed in Table 2. There we report the sample means and the sample standard deviations of the monthly percentage rates of return for these 11 stocks along with their sample betas, computed with respect to the index of all stocks on the NYSE and AMEX (the total portfolio). We also report there the change in the total portfolio's standard deviation with a $\$ 1$ increase in the holdings of any of the stocks. If, as we have found above, $d S / d x_{i}=\beta_{i} S_{p}$, then we should observe that across stocks those changes $\left(\partial S / \partial x_{i}\right)$ are a scale multiple of the betas for the 11 stocks. Chart 2 plots the incremental standard deviation, $\partial S / \partial x_{i}$, against the beta for each asset $i$. Notice that the points lie on a positively sloped straight line; that is, the beta of an asset does measure the incremental risk. Chart 3 plots $\partial S / \partial x_{i}$ against $S_{i}$. Notice that this relationship has no particular pattern; that is, the volatility of the return on the asset is not the right measure of its riskiness.
When the CAPM assumptions are satisfied, everyone in the economy will hold all risky assets in the same proportion. Hence, the betas computed with reference to every individual's portfolio will be the same, and we might as well compute betas using the market portfolio of all assets in the economy. The CAPM predicts that the ratio of the risk premium to the beta of every asset is the same. That is, every investment opportunity provides the same amount of compensation for any given level of risk, when beta is used as the measure of risk.

\section{The Tests}

Now we want to see how the CAPM measures up to the data. As we shall see, there's some debate about that.

\section{Methods}

If expected returns and betas were known, then all we would have to do to examine the empirical support for the CAPM is to plot the return and beta data against each other. Unfortunately, neither of these is known. We have to 
form estimates of them to use in empirical tests. We do this by assuming that sample analogs correspond to population values plus some random noise. The noise is typi-

\section{Chart 2-3}

\section{Beta vs. Return Volatility as the Right Measure of Risk}

The Relationship Between Alternative Risk Measures

and the Effect on a Total Portfolio's Variability

of Investing an Extra Dollar in Each of 11 Stocks*

\section{Chart 2 Beta of the Stock}

Porttolio

S.D. Change

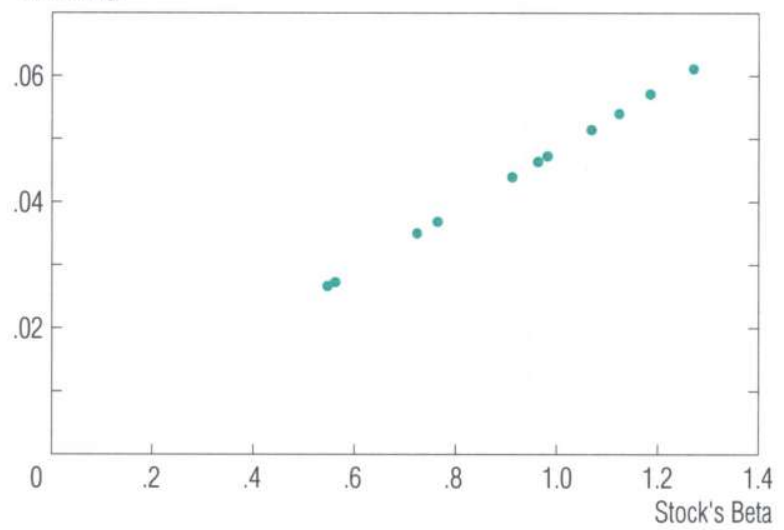

Chart 3 Standard Deviation of the Stock Return

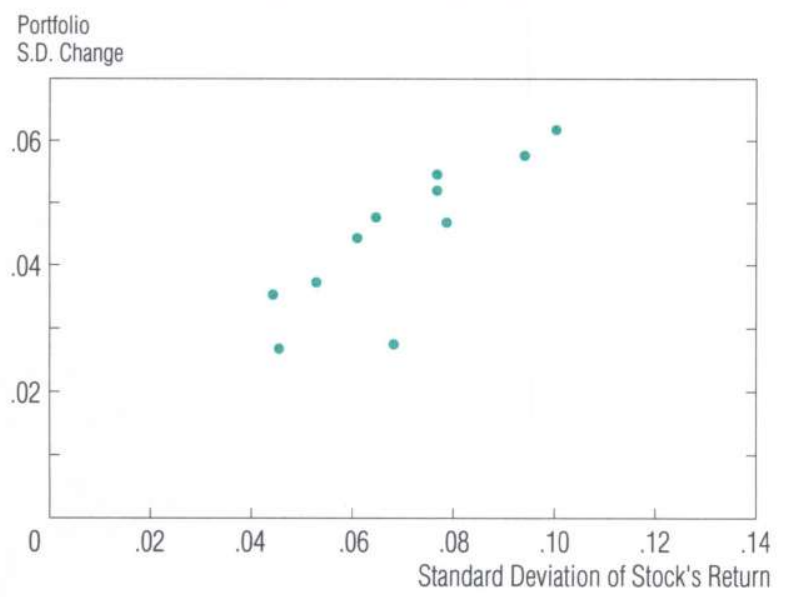

*The stocks are listed in Table 2. The total portfolio is $\$ 1,000$ invested in all stocks traded on the NYSE and AMEX.

Source of basic data: Center for Research on Security Prices, University of Chicago cally very large for individual assets, but less for portfolios. To understand why noise creates problems, notice that two portfolios with measured betas that are very different could well have the same population betas if the measurement error is very large. The objectives are to have sufficient dispersion in asset betas and to measure this dispersion sufficiently precisely.

Black, Jensen, and Scholes (1972) came up with a clever strategy that creates portfolios with very different betas for use in empirical tests. They estimate betas based on history (by regressing historical returns on a proxy for the market portfolio), sort assets based on historical betas, group assets into portfolios with increasing historical betas, hold the portfolios for a selected number of years, and change the portfolio composition periodically. As long as historical betas contain information about population betas, this procedure will create portfolios with sufficient dispersion in betas across assets.

Because this method uses estimates of the expected return and beta, the relation being examined using data is not (10) or (11) but rather

$$
r_{p}=\gamma_{0}+\gamma_{1} b_{p}+\varepsilon_{p}
$$

where $r_{p}$ is an estimate of the expected excess return on portfolio $p$ (the difference between the return on the portfolio and the return on a risk-free asset); $b_{p}$ is an estimate of beta for portfolio $p ; \gamma_{1}$ is the market price of risk, the risk premium for bearing one unit of beta risk; $\gamma_{0}$ is the zero-beta rate, the expected return on an asset which has a beta of zero; and $\varepsilon_{p}$ is a random disturbance term in the regression equation. Black, Jensen, and Scholes (1972) use time series data on returns to construct a sample average for $r_{p}\left(r_{p}=\sum_{t=1}^{T} r_{p, t} / T\right.$, where $r_{p, t}$ is the excess return at time $t$ ). However, there are problems with the standard errors on $\gamma_{0}$ and $\gamma_{1}$ obtained by a least squares regression of average excess returns on estimated betas. Therefore, Black, Jensen, and Scholes suggest computing the standard errors of the parameters in the cross-sectional regression in the following way: First run a cross-sectional regression for each period for which data on returns are available. This procedure generates a time series of parameter estimates. Then use the standard deviation of the estimated time series of parameters as the standard error of the parameter in the cross-sectional regression. ${ }^{5}$

\footnotetext{
${ }^{5}$ For a discussion on computing the sampling errors associated with the estimates of the coefficients in the cross-sectional regression, see Shanken 1992 and Jagannathan
} 
For the original Sharpe (1964) and Lintner (1965) version of the CAPM, $\gamma_{0}$ should be equal to zero and $\gamma_{1}$ should be equal to the risk premium for the market portfolio. For the Black (1972) version of the CAPM, given in equation (11), $\gamma_{0}$ is not necessarily equal to zero. If we take a parameter estimate and divide by its standard error, we can construct a $t$-statistic for that coefficient. If the absolute value of the $t$-statistic is large (greater than 2), then the coefficient is said to be statistically different from zero. Usually, empirical tests of the CAPM are based on the $t$ statistics of the coefficients in the regression equation (15).

According to the CAPM, expected returns vary across assets only because the assets' betas are different. Hence, one way to investigate whether the CAPM adequately captures all important aspects of reality is to test whether other asset-specific characteristics can explain the cross-sectional differences in average returns that are unrelated to cross-sectional differences in beta. To do this, additional terms are added to equation (15):

$$
r_{p}=\gamma_{0}+\gamma_{1} b_{p}+\gamma_{2} \psi_{p}+\varepsilon_{p}
$$

The vector $\psi_{p}$ in (16) corresponds to additional factors assumed to be relevant for asset pricing. In empirical evaluations of the CAPM, researchers want to know if $\gamma_{2}=0$ holds - that is, if beta is the only characteristic that matters.

\section{Classic Support}

One of the earliest empirical studies of the CAPM is that of Black, Jensen, and Scholes (1972). They find that the data are consistent with the predictions of the CAPM, given the fact that the CAPM is an approximation to reality just like any other model.

Black, Jensen, and Scholes (1972) use all of the stocks on the NYSE during 1931-65 to form 10 portfolios with different historical beta estimates. They regress average monthly excess returns on beta. Chart 4 shows their fitted relation between beta and the average excess monthly return (where the risk-free asset is the 30-day T-bill) for these 10 portfolios and a proxy for the total market portfolio. The average monthly excess return on the market proxy used in the study is 1.42 percent. The estimated slope for the resulting regression line is 1.08 percent instead of 1.42 percent as predicted by the CAPM. The estimated intercept is 0.519 percent instead of zero as predicted by the CAPM. The $t$-statistics that Black, Jensen, and Scholes report indicate that the slope and the intercept
Chart 4

\section{A Classic Test of the CAPM}

Average Monthly Returns vs. Beta

for 10 Portfolios and a Market Portfolio

During 1931-65

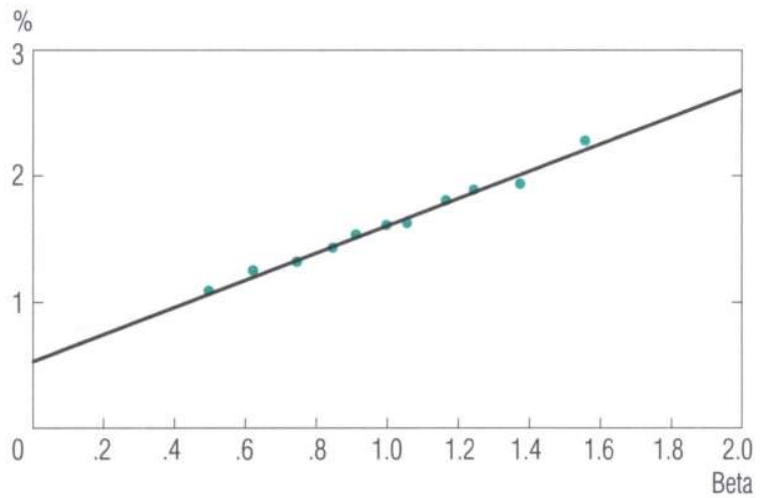

Source: Black, Jensen, and Scholes 1972

of their regression line are significantly different from their theoretical values.

This does not necessarily mean that the data do not support the CAPM, however. As Black $(1972,1993)$ points out, these results can be explained in two plausible ways. One is measurement and model specification error that arises due to the use of a proxy instead of the actual market portfolio. This error biases the regression line's estimated slope toward zero and its estimated intercept away from zero. ${ }^{6}$ The other plausible explanation is simpler: if no risk-free asset exists, then the CAPM does not predict an intercept of zero. In fact, Black, Jensen, and Scholes (1972) conclude that the data are consistent with Black's (1972) version of the model [equation (11)].

To illustrate the empirical method used in the Black, Jensen, and Scholes study, let's evaluate the CAPM using the sample data on stocks, bonds, and bills that we de-

and Wang, forthcoming. For a description of better alternatives for econometric evaluation of the CAPM that rely on either the method of maximum likelihood or the generalized method of moments, see Gibbons 1982, Stambaugh 1982, Shanken 1985, Mackinlay and Richardson 1991, and Jagannathan and Wang 1993.

${ }^{6}$ Suppose the relation being estimated is $y_{t}=\gamma x_{t}+u_{t}$. If we observe $X_{t}=x_{t}+v_{t}$ rather than just $x_{t}$, where $v_{t}$ is measurement error uncorrelated with $x_{t}$, then the least squares estimate for $\gamma$ will be biased toward zero. The larger is the variance of $v_{t}$, the greater is the bias. 
scribed earlier. In Chart 5, we plot the average returns of those assets for the period from 1926 to 1991 against their estimated betas. These estimates of beta-as well as those for the subperiods-are reported in Table 3. We also fit a straight line to the data by running a linear regression. Notice in Chart 5 that the relation between average return and beta is very close to linear and that portfolios with high (low) betas have high (low) average returns. This positive relationship is consistent with the CAPM prediction and the findings reported by Black, Jensen, and Scholes.

Another classic empirical study of the CAPM is by Fama and MacBeth (1973). They examine whether there is a positive linear relation between average return and beta and whether the squared value of beta and the volatility of the return on an asset can explain the residual variation in average returns across assets that is not explained by beta alone. Using return data for the period from 1926 to 1968 , for stocks traded on the NYSE, Fama and MacBeth find that the data generally support the CAPM.

\section{Challenges}

The CAPM thus passed its first major empirical tests. In 1981, however, a study suggested that it might be missing something. A decade later, another study suggested that it might be missing everything, and the debate about the CAPM's value was on.

\section{What About Firm Size?}

Banz (1981) tests the CAPM by checking whether the size of the firms involved can explain the residual variation in average returns across assets that is not explained by the CAPM's beta. Banz challenges the CAPM by showing that size does explain the cross-sectional variation in average returns on a particular collection of assets better than beta. He finds that during the 1936-75 period, the average return to stocks of small firms (those with low values of market equity) was substantially higher than the average return to stocks of large firms after adjusting for risk using the CAPM. This observation has become known as the size effect.

Banz (1981) uses a procedure similar to the portfoliogrouping procedure of Black, Jensen, and Scholes (1972). The assets are first assigned to one of five subgroups, based on their historical betas. Stocks in each of the subgroups are then assigned to five further subgroups, based on the market value of the firms' equities. This produces total of 25 portfolios. Portfolios are updated at the end of each year. Banz uses firms on the NYSE and estimates the cross-sectional relation between return, beta, and rela-
Chart 5

\section{Repeating a Classic Test of the CAPM}

Average Annual Returns vs. Beta for Four Types of Assets: S\&P 500 and Small-Firm Stocks and U.S. Treasury Bonds and Bills During 1926-91

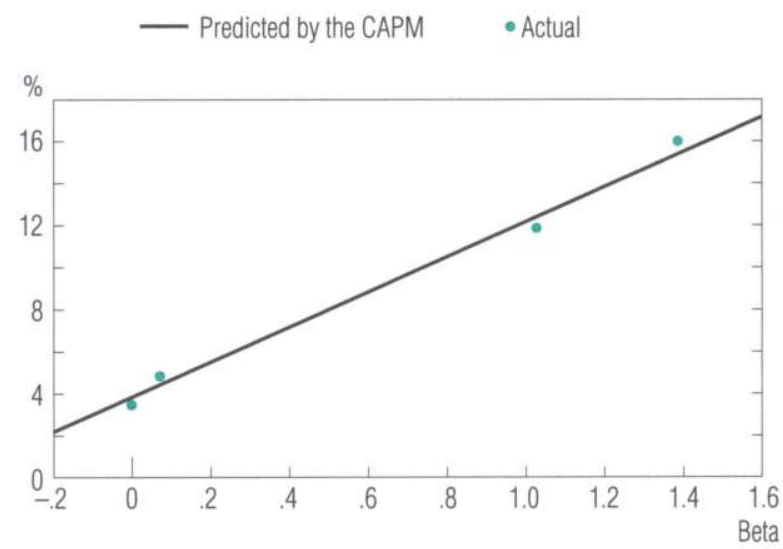

Source: Ibbotson Associates 1992

tive size - that is, our equation (16) with $\psi_{p}$ equal to the relative size of the $p$ th portfolio. With this procedure, then, in (16), $\gamma_{0}$ is the rate of return for a portfolio with beta equal to zero, and $\gamma_{1}$ and $\gamma_{2}$ are risk premiums for beta and size risks, respectively.

Banz (1981) reports estimates for $\gamma_{0}-R_{0}$ and $\gamma_{1}-$ $\left(R_{m}-R_{0}\right)$, where $R_{0}$ and $R_{m}-R_{0}$ are the intercept and the slope predicted by the CAPM. The idea is to report deviations from theory. Theory predicts that $\gamma_{0}=R_{0}, \gamma_{1}=R_{m}-$ $R_{0}$, and $\gamma_{2}=0$. If deviations from theory are statistically significant (if the $t$-statistics are large in absolute value), then Banz would conclude that the CAPM is misspecified. For the entire period, 1936-75, Banz obtains the following estimates (and $t$-statistics): $\hat{\gamma}_{0}-R_{0}=0.0045$ (2.76), $\hat{\gamma}_{1}-$ $\left(R_{m}-R_{0}\right)=-0.00092(-1.0)$, and $\hat{\gamma}_{2}=-0.00052(-2.92)$, where $R_{m}$ is a measure of the market return. Because the $t$-statistic for $\gamma_{2}$ is large in absolute value, Banz concludes that the size effect is large and statistically significant. The fact that the estimate for $\gamma_{2}$ is negative implies that stocks of firms with large market values have had smaller returns on average than stocks of small firms. From these results, relative size seems to be able to explain a larger fraction of the cross-sectional variation in average return than beta can. 
Table 3

Estimated Betas for Four Types of Assets

During 1926-91

\begin{tabular}{lcccccr}
\hline & \multicolumn{2}{c}{ Stocks } & & \multicolumn{2}{c}{ U.S. Treasury } \\
\cline { 2 - 3 } Period & S\&P 500 & Small Firms & & Bonds & Bills \\
\hline $1926-91$ & 1.03 & 1.39 & & .07 & .00 \\
$1926-75$ & 1.03 & 1.44 & & .03 & .00 \\
$1976-80$ & .94 & 1.46 & & .22 & .00 \\
$1981-91$ & 1.01 & .99 & & .31 & -.01 \\
\hline
\end{tabular}

Source of basic data: Ibbotson Associates 1992

To assess the importance of these results, Banz (1981) does one additional test. He constructs two portfolios, each with 20 assets. One portfolio contains only stocks of small firms, whereas the other contains only stocks of large firms. The portfolios are chosen in such a way that they both have the same beta. Banz finds that, during the time period 1936-75, the small-firm portfolio earned on average 1.48 percent per month more than the large-firm portfolio, and the differences in returns are statistically significant. Thus, the CAPM seems to be missing a significant factor: firm size.

\section{Is Beta Dead?}

The general reaction to Banz's (1981) finding that the CAPM may be missing some aspect of reality was, Of course: since the CAPM is only an abstraction from reality, expecting it to be exactly right is unreasonable. While the data may show some systematic deviations from the CAPM, these are not economically important enough to reject it. This view has been challenged by Fama and French (1992). They show that Banz's finding may be economically so important that it questions the validity of the CAPM in any economically meaningful sense.

Fama and French (1992) estimate the relation in equation (16) for the period from July 1963 to December 1990 with $\psi_{p}$ equal to size. They group stocks for firms listed on the NYSE, AMEX, and NASDAQ (the National Association of Securities Dealers Automated Quotations) into 10 size classes and then into 10 beta classes, for a total of 100 portfolios. They obtain estimates of $\gamma_{1}=-0.37$ with a $t$-statistic of -1.21 and $\gamma_{2}=-0.17$ with a $t$-statistic of -3.41 . Furthermore, even when they include only beta in the regression equation [equation (15)], they do not find a significantly positive slope; their estimate for $\gamma_{1}$ is -0.15 with a standard error of 0.46 . However, the size effect is significant with or without betas. Thus, their estimates indicate that, for a large collection of stocks, beta has no ability to explain the cross-sectional variation in average returns, whereas size has substantial explanatory power.

Fama and French (1992) also consider the ability of other attributes to account for this cross-sectional variation. When they include the ratio of the book value of a firm's common equity to its market value as an explanatory variable in addition to size, they find that this ratio can account for a substantial portion of the cross-sectional variation in average returns. In fact, book-to-market equity appears to be more powerful than size.

What is so surprising about these results is that Fama and French (1992) use the same procedure as Fama and MacBeth (1973) but reach a very different conclusion: Fama and MacBeth find a positive relation between return and risk, and Fama and French find no relation at all. Fama and French attribute the different conclusions to the different sample periods used in the two studies. Recall that Fama and MacBeth (1973) use stock returns for 192668, whereas Fama and French (1992) use stock returns for 1963-90. When Fama and French rerun their regressions for 1941-65, they find a positive relationship between average return and beta.

The sensitivity of the conclusions to the sample period used can be illustrated using our four-asset data set. Suppose we repeat the exercise of Chart 5 for several subperiods. In Chart 6, we plot the average returns of our four types of assets for the first subperiod, 1926-75, against their estimated betas. A straight line is fit to the data by running a linear regression. Notice that Chart 6 is very similar to Chart 5 , which includes the entire sample period. In both charts, we see a positive, linear relationship between average return and beta.

For the subperiods 1976-80 and 1981-91, however, we do not see that relationship. Consider first the plot in Chart 7 for the period 1976-80. In these years, small-firm stocks gave an usually higher return of 35.6 percent while the S\&P 500 gave only a more-usual 14.2 percent. Meanwhile, Treasury bills did much better than usual, and Treasury bonds did worse. Consider next the plot in Chart 8 for the period 1981-91. Notice that the small-firm effect disappeared in this period. The S\&P 500 stocks yielded an 


\section{Chart 6-8}

A Changing Relationship

Between Average Annual Returns and Beta for Four Types of Assets

\section{- Predicted by the CAPM • Actual}
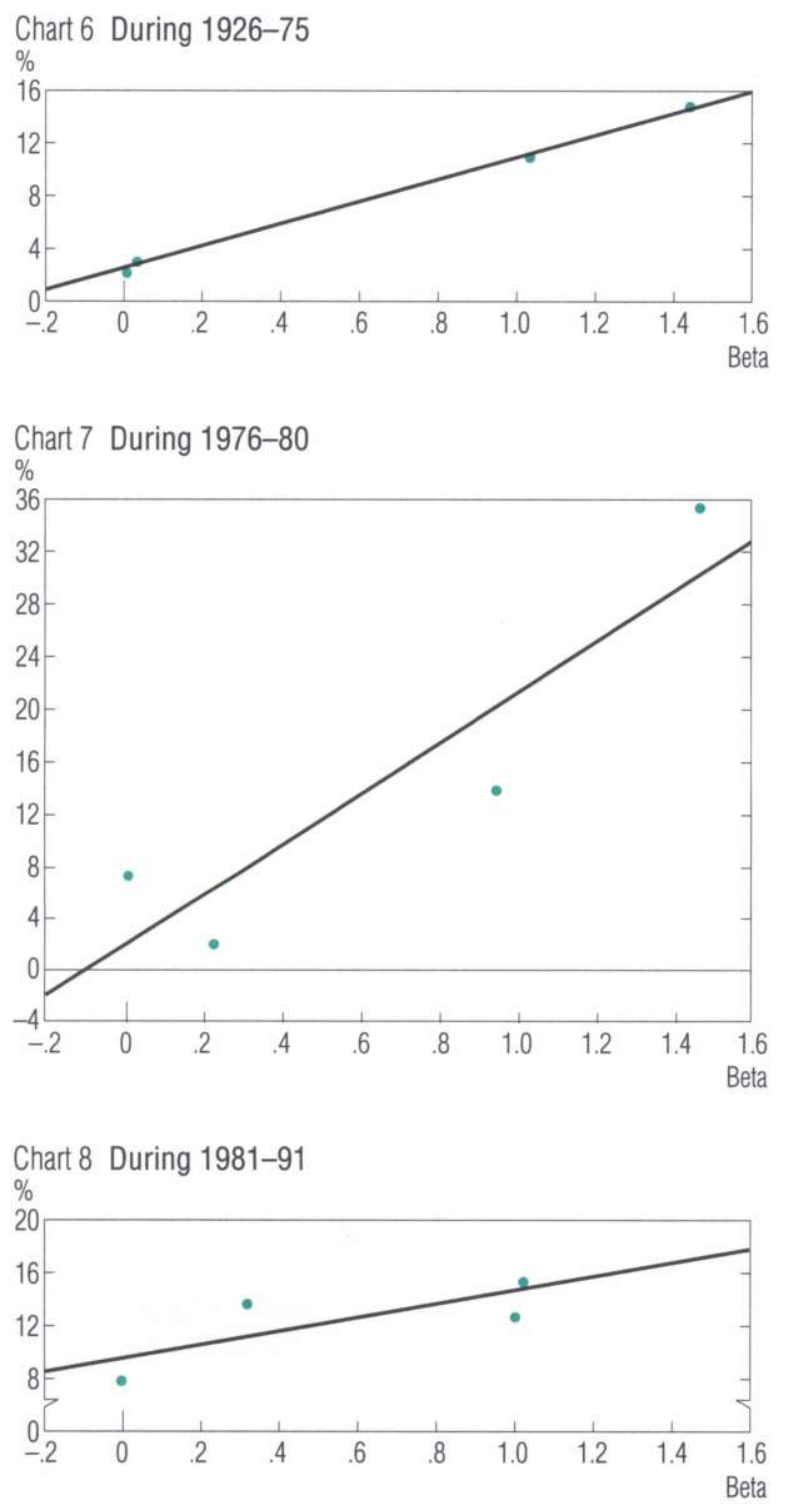

Source of basic data: Ibbotson Associates 1992 average return of 15.7 percent, and the return on small stocks was only 13.3 percent. Yet the two types of assets have approximately the same beta value. This fact is counter to the prediction of the CAPM. Thus, although we find empirical support for the CAPM over a long horizon (1926-91 or 1926-75), there are periods in which we do not find it.

The evidence against the CAPM can be summarized as follows. First, for some sample periods, the relation between average return and beta is completely flat. Second, other explanatory variables such as firm size (market equity) and the ratio of book-to-market equity seem to do better than beta in explaining cross-sectional variation in average asset returns.

\section{Responses}

\section{What About the Data?}

The Fama and French (1992) study has itself been challenged. The study's claims most attacked are these: that beta has no role for explaining cross-sectional variation in returns, that size has an important role, and that the bookto-market equity ratio has an important role. The studies responding to the Fama and French challenge generally take a closer look at the data used in that study.

Kothari, Shanken, and Sloan (1995) argue that Fama and French's (1992) findings depend critically on how one interprets their statistical tests. Kothari, Shanken, and Sloan focus on Fama and French's estimates for the coefficient on beta $\left[\gamma_{1}\right.$ in equation (15)], which have high standard errors and therefore imply that a wide range of economically plausible risk premiums cannot be rejected statistically. For example, if the estimate of $\gamma_{1}$ is 0.24 percent per month with a standard error of 0.23 percent, then 0 and 50 basis points per month are both statistically plausible. ${ }^{7}$

This view, that the data are too noisy to invalidate the CAPM, is supported by Amihud, Christensen, and Mendelson (1992) and Black (1993). In fact, Amihud, Christensen, and Mendelson (1992) find that when a more efficient statistical method is used, the estimated relation between average return and beta is positive and significant.

Black (1993) suggests that the size effect noted by Banz (1981) could simply be a sample period effect: the size effect is observed in some periods and not in others. To make his point, Black uses some findings of Fama and French (1992). They find that their estimate of $\gamma_{2}$ in equa-

\footnotetext{
${ }^{7}$ These figures are from Fama and French's (1992) regressions of individual NYSE stocks on beta for 1941-90.
} 
tion (16) is not significantly different from zero for the 1981-90 period. That is, size does not appear to have any power to explain cross-sectional variation in average returns for the period after the Banz (1981) paper was published. This point is also evident in our data in Table 1. In the 1981-91 subperiod, the return on small-firm stocks was 13.3 percent whereas that on the S\&P 500 stocks was 15.7 percent.

One aspect of Fama and French's (1992) result is troubling. Although their point estimate for the coefficient on beta $\left(\gamma_{1}\right)$ for the 1981-90 sample is statistically significant, it is negative rather than positive, as the CAPM predicts risk premiums to be. This is evidence against the CAPM, but also evidence in favor of the view that the size effect may be spurious and period-specific.

Even if there is a size effect, however, there is still a question about its importance given the relatively small value of small firms, as a group, used in these studies. Jagannathan and Wang (1993) report the average market value of firms in each of 100 groups. Firms in the largest 40 percent of the groups account for more than 90 percent of the market value of all stocks on the NYSE and AMEX. Thus, for a large enough collection of assets, the CAPM may still be empirically valid.

Another variable that Fama and French (1992) find to be important for explaining cross-sectional variation in returns is the ratio of book-to-market equity. However, Kothari, Shanken, and Sloan (1995) point to another problem with the data (from Compustat) used by Fama and French (1992). ${ }^{8}$ The problem is the treatment of firms that are added to the data set and then their data are back-filled by Compustat. Firms that had a high ratio of book-to-market equity early in the sample were less likely to survive and less likely to be included by Compustat. Those that did survive and were added later show high returns. Thus, the procedure has a potential bias. Breen and Korajczyk (1993) follow up on this conjecture by using a Compustat sample that has the same set of firms for all years; no back-filled data are used. They find that the effect of the book-to-market equity ratio is much weaker in these data than that reported by Fama and French (1992). ${ }^{9}$

\section{Is Beta Alive?}

The general reaction to the Fama and French (1992) findings, despite these challenges, has been to focus on alternative asset pricing models (for example, the interesting one in Fama and French 1993). Jagannathan and Wang (1993) think that may not be necessary. Instead they show that the lack of empirical support for the CAPM may be due to the inappropriateness of some assumptions made to facilitate the empirical analysis of the model. Such an analysis must include a measure of the return on the aggregate wealth portfolio of all agents in the economy, and Jagannathan and Wang say most CAPM studies do not do that.

Most empirical studies of the CAPM assume, instead, that the return on broad stock market indexes, like the NYSE composite index, is a reasonable proxy for the return on the true market portfolio of all assets in the economy. However, in the United States, only one-third of nongovernmental tangible assets are owned by the corporate sector, and only one-third of corporate assets are financed by equity. Furthermore, intangible assets, like human capital, are not captured by stock market indexes.

Jagannathan and Wang (1993) abandon the assumption that the broad stock market indexes are adequate. Following Mayers (1972), they include human capital in their measure of wealth. Since human capital is, of course, not directly observable, Jagannathan and Wang must use a proxy for it. They choose the growth of labor income.

They build human capital into the CAPM this way: Let $R_{v w}$ be the return to the value-weighted portfolio of all stocks traded on the NYSE and AMEX, and let $R_{l}$ be the growth rate of per capita labor income. Then Jagannathan and Wang's version of the CAPM is given by

$$
E R_{p}=\alpha_{0}+\alpha_{1} \beta_{p}^{v w}+\alpha_{2} \beta_{p}^{l}
$$

where $E R_{p}$ is the expected return on portfolio $p$, $\beta_{p}^{v w}$ is the risk of portfolio $p$ relative to the value-weighted portfolio of all stocks traded on the NYSE and AMEX $\left[\operatorname{cov}\left(R_{p}, R_{v w}\right) / \operatorname{var}\left(R_{v w}\right)\right]$, and $\beta_{p}^{l}$ is the risk of portfolio $p$ relative to wealth due to human capital $\left[\operatorname{cov}\left(R_{p}, R_{l}\right) / \operatorname{var}\left(R_{l}\right)\right]$.

With human capital included in this way, Jagannathan and Wang (1993) show that the CAPM is able to explain 28 percent of the cross-sectional variation in average returns in the 100 portfolios studied by Fama and French (1992). Since only 1.4 percent of the cross-sectional variation can be explained by a traditional market portfolio that

\footnotetext{
${ }^{8}$ Chari, Jagannathan, and Ofer (1988) also point out this bias in the Compustat data.

${ }^{9}$ Compustat claims that it rarely adds more than two years of back data when it adds a firm to its list. In view of this, in their follow-up article, Fama and French (1993) omit the first two years of data, but they still find that average returns are strongly related to the book-to-market equity ratio in the cross section. Hence, the reason for this effect is still unknown.
} 
includes only stocks on the NYSE and AMEX, the addition of human capital makes a significant difference.

Jagannathan and Wang (1993, forthcoming) also look in another direction. Several studies have pointed out that betas of assets vary over the business cycle in a systematic way (for example, Harvey 1989; Ferson and Harvey 1991, 1993; and Ferson and Korajczyk 1995). When Jagannathan and Wang (1993, forthcoming) also allow for timevarying betas, they show that the CAPM is able to explain 57 percent of the cross-sectional variation in average returns. They show that not all time variations in beta matter-only those that comove with the expected risk premium on the market portfolio. Since the market risk premium is highly correlated with other macroeconomic aggregates that also vary over the business cycle, only the part of the time variation in the asset's beta that can be predicted using variables that help forecast the business cycle matters for explaining expected returns.

To build this part into the CAPM, let $R_{p r}$ be the difference between the yields on low- and high-grade bonds. Jagannathan and Wang (1993, forthcoming) assume that $R_{p r}$ is a good indicator of the business cycle and, hence, of cyclical movements in beta. They show that the CAPM with time-varying betas and human capital implies the following three-beta model for unconditional expected returns:

$$
E R_{p}=\alpha_{0}+\alpha_{1} \beta_{p}^{v w}+\alpha_{2} \beta_{p}^{l}+\alpha_{3} \beta_{p}^{p r}
$$

where $\beta_{p}^{p r}=\operatorname{cov}\left(R_{p, t}, R_{p r t-1}\right) / \operatorname{var}\left(R_{p, t}\right)$. In (18), $\beta_{p}^{p r}$ provides a measure of the instability of the beta of portfolio $p$. If we hold other things constant, then assets with larger beta instability should earn a higher expected return. When Jagannathan and Wang (1993, forthcoming) include firm size in (18), they find that size has little ability to explain what is left unexplained by the three-beta model.

In Charts 9-11, we reproduce Figures 1, 3, and 4 of Jagannathan and Wang (forthcoming) which illustrate the performance of the various versions of their model. All versions use data for 100 portfolios of stocks traded on the NYSE and AMEX during July 1963-December 1990. Chart 9 is based on a standard CAPM. It is a plot of the realized average returns against the fitted expected returns using estimated parameters when only $\beta_{p}^{v w}$ is included in the regression equation. If the predictions of the model are consistent with the data, the points should lie on the 45degree line. Clearly, they don't. With only stock betas included in the model, the fitted expected returns are all
Chart 9-11

The Effects of Modifying the CAPM

Fitted Expected Returns vs. Realized Average Returns for 100 Portfolios of NYSE and AMEX Stocks

During July 1963-December 1990

Chart 9 A Standard One-Beta Model

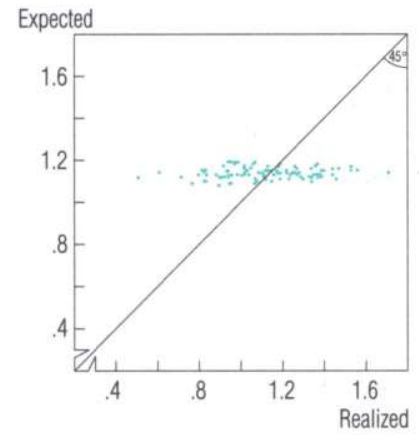

Chart 10 A Model With Human Capital and Time-Varying Betas ...

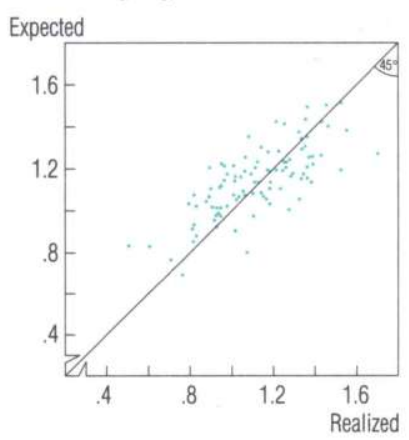

Chart 11 ... And Firm Size

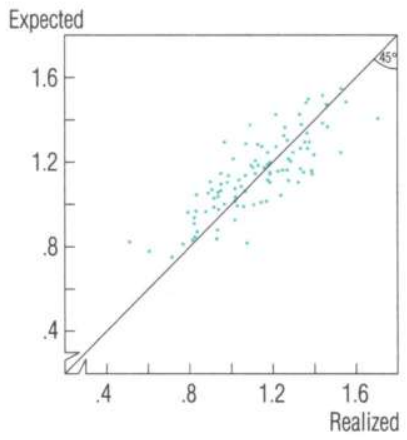

Source: Jagannathan and Wang, forthcoming (Figures 1, 3, and 4) 
about the same despite the variation in realized average returns. Chart 10 shows the effect of adding human capital and time-varying betas to the model. Now the cluster of points comes close to lining up on the 45-degree line; the performance of the model improves significantly with $\beta_{p}^{l}$ and $\beta_{p}^{p r}$ included. Finally, Chart 11 shows what happens when the model includes size as well. The fact that Charts 10 and 11 look so much alike is consistent with the prediction that beta alone is the relevant variable for explaining average returns.

Thus, Jagannathan and Wang (1993, forthcoming) directly respond to the challenge of Fama and French (1992, p. 449), who assert that "resuscitation of the SLB [Sharpe 1964-Lintner 1965-Black 1972] model requires that a better proxy for the market portfolio (a) overturns our evidence that the simple relation between $\beta$ and average stock returns is flat and (b) leaves $\beta$ as the only variable relevant for explaining average returns." The version of the CAPM that Jagannathan and Wang use has three betas and hence does not meet condition (b). Therefore, perhaps their results should be viewed not as a modification of the CAPM but rather as the development of a new asset pricing model. However, Jagannathan and Wang demonstrate that when the use of a better proxy (including human capital) for the market portfolio results in a two-beta model instead of a one-beta model and when the CAPM holds in a conditional sense (period-by-period with betas and expected returns varying over time), unconditional expected returns will be linear with market beta as well as a measure of beta instability over business cycles. One could therefore argue that the CAPM really implies that more than beta is needed to explain the cross section of expected returns on financial assets.

\section{In Sum}

To summarize, although Fama and French (1992) make a persuasive case against the CAPM, recent studies have challenged their results. There have also been modifications of the Sharpe 1964-Lintner 1965-Black 1972 CAPM not considered by Fama and French (1992) that appear to be consistent with the data. Whether or not these alternative models will themselves withstand further scrutiny is yet to be determined.

\section{Concluding Remarks}

With academics debating the value of the CAPM, what are companies that now use it in their capital budgeting process to do? Maybe nothing different. Obviously, capital budgeting decisions were made before there was a CAPM, and they can be made again without it. But the data seem to suggest that those who choose to use the CAPM now despite the academic debate will actually not be getting worthless advice. Recall our Chart 5 , where we plotted the return/beta relationship for four types of assets over a period as long as 66 years. The result was more-or-less a positively sloped, straight line, just as the CAPM predicts. As we saw, that straight-line relationship breaks down over shorter time periods, and academics continue to debate why that is so. But for now, for those interested in the longer view, the CAPM still seems to have something to offer. 


\section{References}

Amihud, Yakov; Christensen, Bent Jesper, and Mendelson, Haim. 1992. Further evidence on the risk-return relationship. Working Paper S-93-11. Salomon Brothers Center for the Study of Financial Institutions, Graduate School of Business Administration, New York University.

Banz, Rolf W. 1981. The relationship between return and market value of common stocks. Journal of Financial Economics 9 (March): 3-18.

Black, Fischer. 1972. Capital market equilibrium with restricted borrowing. Journal of Business 45 (July): 444-55.

1993. Beta and return. Journal of Portfolio Management 20 (Fall): 8-18.

Black, Fischer; Jensen, Michael C.; and Scholes, Myron. 1972. The capital asset pricing model: Some empirical tests. In Studies in the theory of capital markets, ed. Michael Jensen, pp. 79-121. New York: Praeger.

Breen, William J., and Korajczyk, Robert A. 1993. On selection biases in book-to-market based tests of asset pricing models. Working Paper 167. Northwestern University.

Chari, V. V.; Jagannathan, Ravi; and Ofer, Aharon R. 1988. Seasonalities in security returns: The case of earnings announcements. Journal of Financial Economics 21 (May): 101-21.

Fama, Eugene F., and French, Kenneth R. 1992. The cross-section of expected stock returns. Journal of Finance 47 (June): 427-65.

1993. Common risk factors in the returns on bonds and stocks. Journal of Financial Economics 33 (February): 3-56.

Fama, Eugene F., and MacBeth, James D. 1973. Risk, return and equilibrium: Empirical tests. Journal of Political Economy 81 (May-June): 607-36.

Ferson, Wayne E., and Harvey, Campbell R. 1991. The variation of economic risk premiums. Journal of Political Economy 99 (April): 385-415.

1993. The risk and predictability of international equity returns. Review of Financial Studies 6 (3): 527-66.

Ferson, Wayne E., and Korajczyk, Robert A. 1995. Do arbitrage pricing models explain the predictability of stock returns? Journal of Business 68 (July): 309-49.
Gibbons, Michael R. 1982. Multivariate tests of financial models: A new approach. Journal of Financial Economics 10 (March): 3-27.

Harvey, Campbell R. 1989. Time-varying conditional covariances in tests of asset pricing models. Joumal of Financial Economics 24 (October): 289-317.

Ibbotson Associates. 1992. Stocks, bonds, bills, and inflation-1992 yearbook. Chicago: Ibbotson Associates.

Jagannathan, Ravi, and Wang, Zhenyu. 1993. The CAPM is alive and well. Research Department Staff Report 165. Federal Reserve Bank of Minneapolis.

. Forthcoming. The conditional CAPM and the cross-section of expected returns. Joumal of Finance.

Kothari, S. P.; Shanken, Jay; and Sloan, Richard G. 1995. Another look at the crosssection of expected stock returns. Journal of Finance 50 (March): 185-224.

Lintner, John. 1965. The valuation of risk assets and the selection of risky investments in stock portfolios and capital budgets. Review of Economics and Statistics 47 (February): 13-37.

Mackinlay, A. Craig, and Richardson, Matthew P. 1991. Using generalized method of moments to test mean-variance efficiency. Journal of Finance 46 (June) $511-27$.

Mayers, David. 1972. Nonmarketable assets and capital market equilibrium under uncertainty. In Studies in the theory of capital markets, ed. Michael Jensen, pp. 223-48. New York: Praeger.

Shanken, Jay. 1985. Multivariate tests of the zero-beta CAPM. Journal of Financial Economics 14 (September): 327-48.

1992. On the estimation of beta-pricing models. Review of Financial Studies 5 (1): 1-33.

Sharpe, William F. 1964. Capital asset prices: A theory of market equilibrium under conditions of risk. Journal of Finance 19 (September): 425-42.

Stambaugh, Robert F. 1982. On the exclusion of assets from tests of the two-parameter model: A sensitivity analysis. Journal of Financial Economics 10 (November) $237-68$. 